\title{
Leakage Current Waveforms and Arcing Characteristics of Epoxy Resin for Outdoor Insulators under Clean and Salt Fogs
}

\author{
Suwarno \& S.K. Ardianto \\ School of Electrical Engineering and Informatics \\ Bandung Institute of Technology \\ Jl. Ganesha 10 Bandung 40132, INDONESIA \\ Email: suwarno@ieee.org
}

\begin{abstract}
Ceramic outdoor insulators have been used in high voltage transmission lines since long time ago. Due to superiority in their resistance to pollution, recently, polymeric outdoor insulators are widely used. Epoxy resin is one polymer which shows good properties for outdoor insulation. During service, outdoor insulators may severe a certain degree of pollution which may reduce their surface resistance. Leakage current (LC) usually increase and degradation may take place. This paper reports experimental results on the leakage current waveforms and arcing characteristics of epoxy resin under clean and salt fog. The samples used are blocks of epoxy resin with dimension of 250 x $50 \times 20 \mathrm{~mm}^{3}$. The samples were put in a test chamber with dimension of $900 \times 900 \times 1200 \mathrm{~mm}^{3}$ with controllable humidity and pollution conditions. Clean and salt fog were generated according to IEC 60-1 and 507. The arcing experiment was done with incline plane test in accordance with IEC 587. AC voltage in the range from $5 \mathrm{kV}$ to $50 \mathrm{kV}$ with frequency of $50 \mathrm{~Hz}$ was applied. The LC waveforms up to flash over were measured. The magnitudes as well as harmonic content of the LC were analyzed. The correlation between LC waveforms and dry band arching phenomenon was elaborated. Visual observation of the arc on the sample surfaces was observed using a video camera. Experimental results indicated that LC magnitude on clean samples was slightly affected by humidity (RH). However, under salt fog, RH greatly affected the LC magnitude. The flashover voltage of clean samples under salt fog reduced significantly for fog conductivity of more than $1.2 \mathrm{mS} / \mathrm{cm}$. Kaolin-polluted samples under salt fog showed an Ohmic behaviour. The LC magnitude was high and a large discrepancy of LC magnitude was observed for high applied voltage of larger than $25 \mathrm{kV}$. The largest LC magnitude was observed on salt-kaolin polluted samples under clean fog at high RH. LC waveforms analysis indicated that in general LC waveforms were distorted from sinusoidal. For clean samples under clean fog, THD of LC decreased with RH but slightly increased with the applied voltage. Large distortion at the peak of LC waveform was observed on kaolin polluted sample under salt fog of $3.6 \mathrm{mS} / \mathrm{cm}$ and high $\mathrm{RH}$ and high applied voltage. This correlates with corona arc on the sample surface. Similar behaviour was observed on kaolin-salt polluted samples under clean fog. Tracking arc experiment indicated that arc length LC magnitude and arc intensity
\end{abstract}


increased with the pollutant conductivity. The THD also significantly increased with pollutant conductivity. At conductivity of less than $0.6 \mathrm{mS} / \mathrm{cm}$ the unsymmetrical LC waveforms were obtained. However, symmetrical LC waveforms were observed for conductivity of 0.9 and $1.2 \mathrm{mS} / \mathrm{cm}$. The change of LC magnitude and waveform at different condition of samples may be useful for the diagnostics of insulator condition.

Keywords: dry band; epoxy resin; humidity; leakage current; waveform; THD; surface resistance.

\section{$1 \quad$ Introduction}

In a power system, insulator plays an important role to isolate among live parts and between live part and ground and as mechanical protector. The insulators are widely used at substations, transmission as well as distribution networks [1].

Due to some superior properties such as lightweight, good water repellance and resistance to pollution, recently, polymeric insulating materials are introduced to substitute conventionally used insulators like porcelains and glasses [2,3]. During service, several severe conditions such as high humidity, coastal and industrial pollutions as well as biological contaminations may be exposed to the outdoor insulators [4-6]. For development of outdoor insulator, laboratory test is useful [7-11].

Laboratrory investigations on a number of polymeric outdoor insulators such as silicone rummber, Ethylene Prophylene Diene Monomer (EPDM), Cycloalipatic resin, Polydimethylsiloxane (PDMS) and RTVand silicone compound coatings have been reported [12-17].

Epoxy resin is one of polymeric materials used for high voltage insulators. Epoxy resin showed a considerable good tracking and errosion resistance and suitable for outdoor use. There are several reports explained good insulation properties of epoxy resin used in polluted conditions [18,19]. However, almost no paper has been reported concerning leakage current and its waveforms for epoxy resin although it is important for insulator diagnostics. This paper reports the experimental results on the leakge current and its waveforms of epoxy resin under various artificial contaminations using clean and salt fog methods.

\section{Experiment}

\subsection{Sample}

The samples used in this experimet were epoxy resin formed from diglycidil ether of bisphenol-A (DGEBA) and metaphenylene-diamine (MPDA) at $27^{\circ} \mathrm{C}$ 
and $1 \mathrm{~atm}$. The samples were prepared in the form of blocks with dimension of $250 \times 50 \times 20 \mathrm{~mm}^{3}$ as shown in Figure 1(a) clean and 1(b) kaolin-salt polluted. For obtaining good contact with electrode, the two ends of the samples were coated with conductive silver paint. The samples was subjected to various test conditions such as clean fog and salt fog, kaolin pollution and kaolin-salt pollution under clean or salt fog. Kaolin-salt pollution was obtained by adding $40 \mathrm{~g}$ kaolin into 1 liter water. Salt was added into the solution for obtaining the desired conductivity. The conductivity was varied from $0.6 \mathrm{mS} / \mathrm{cm}-4.0$ $\mathrm{mS} / \mathrm{cm}$ which represented the degree of pollution from light to heavy derived from Equivalent Salt Deposit Density (ESDD) according to IEC 507[20].

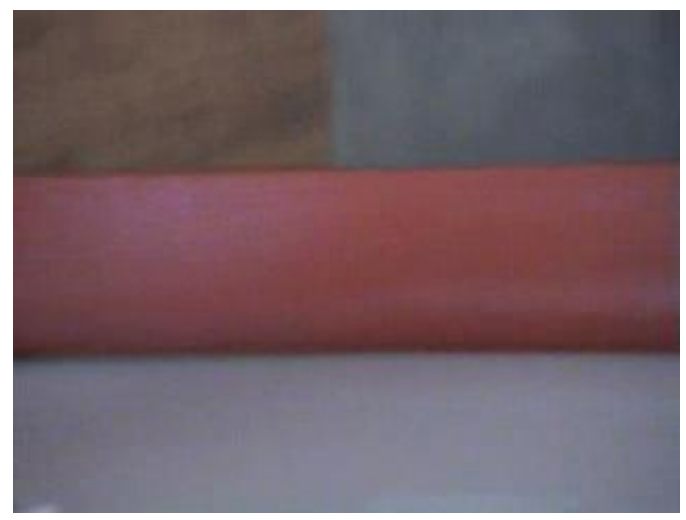

(a)

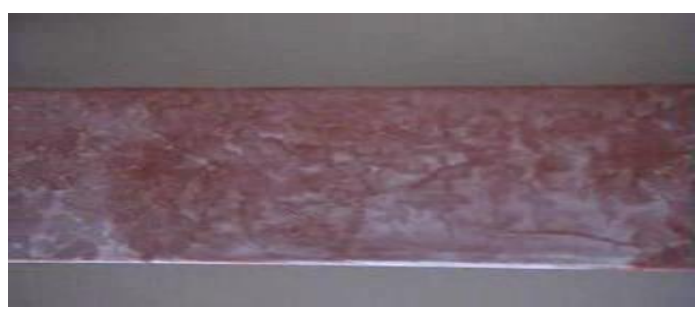

(b)

Figure 1 Epoxy resin samples used in experiment (a) clean (b) kalin-salt polluted. 


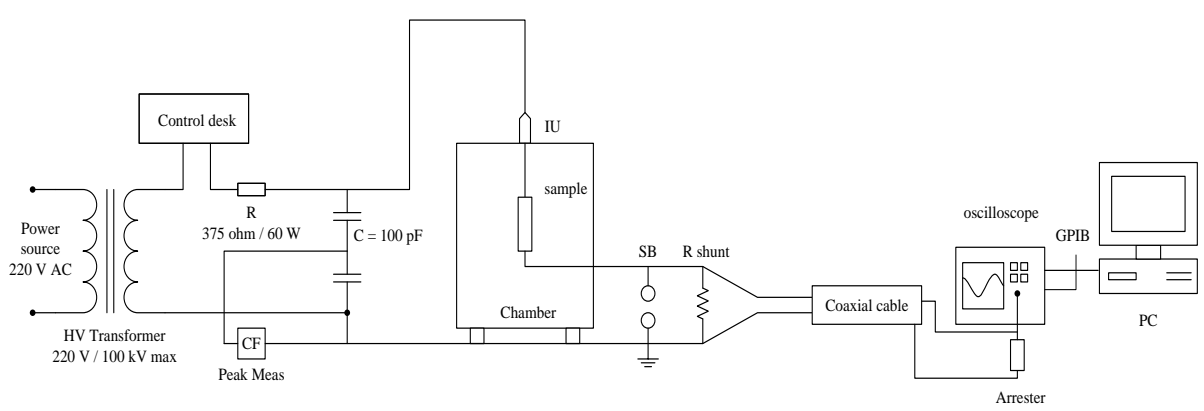

Figure 2 Measurement system

The humidity $(\mathrm{RH})$ of the fog chamber was conditioned at humidity of $50-60 \%$ (low RH), 70-80 \% (medium RH ) or 90-98 \% (high RH). The tests were conducted according to IEC 60-1 (1989)[21] and IEC 507 (fog test) [20].

\subsection{Leakage Current Measurement}

The leakage current flowed on the insulator surface was measured by measuring the voltage across a series resistance of $10 \mathrm{k} \Omega$ using a Digital Oscilloscope with bandwidth of $100 \mathrm{MHz}$, and the maximum sampling rate of $1 \mathrm{GS} / \mathrm{s}$. LC waveforms were digitized and the digital data was transferred to a personal computer trough a GPIB for further analysis. The measurement system is shown in Figure 3. Harmonic content of LC was analyzed using FFT (Fast Fourier Transform). Under polluted conditions, leakage current on the outdoor insulators usually distorted from its sinusoidal form as shown in Figure 3. The degree of distortion is expressed as Total Harmonic Distortion (THD) which is defined as

$$
\mathrm{THD}=\frac{\sqrt{\sum_{n=2}^{\infty} I_{n}{ }^{2}}}{I_{1}}
$$

where $I_{I}$ is fundamental component of LC ( 1 st harmonic) and $I_{n}$ is $n t h$ harmonic component of LC. 


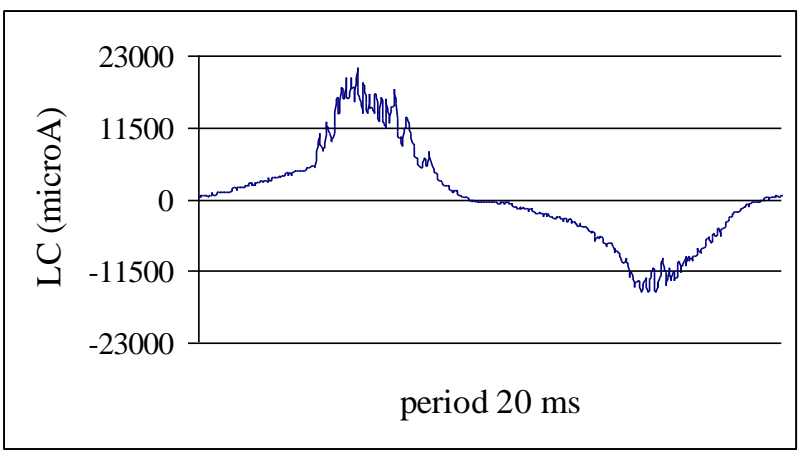

(a)

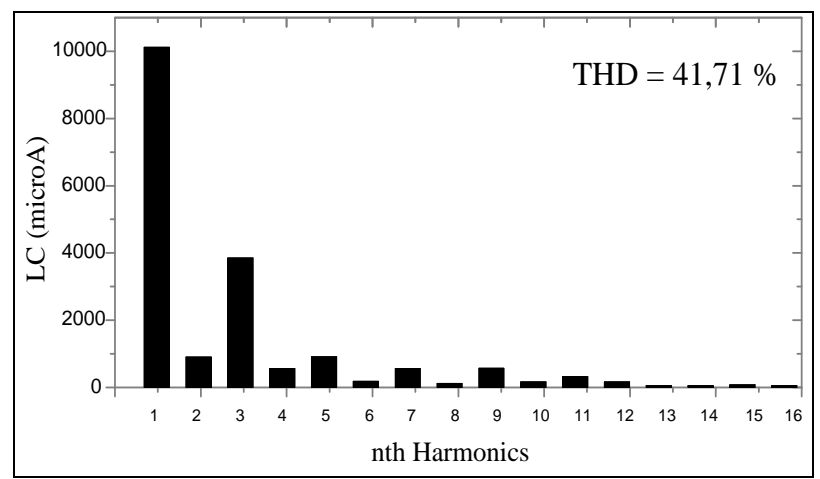

(b)

Figure 3 Typical leakage current on insulator surface (a) and harmonic components (b).

\subsection{Arc Measurement}

In order to observe the arc on the samples, an inclined plane method according to IEC 587 (inclined plane test) [22] was used. The samples were put inclined in a chamber. The pollution and humidity were adjusted and the AC voltage was applied. Arcing took place on the sample surface was observed using a camera, and the corresponding leakage current was measured using LC measurement system as described before.

\subsection{Surface Resitance Measurement}

In order to know the surface resistance of the samples, the resiatance was measured using mega ohm meter at operating voltage of $1000 \mathrm{~V}$. The two ends of the samples were coated with silver paint to form electrodes. 


\section{$3 \quad$ Experimental Results}

\subsection{Leakage Current Characteristics of Clean Samples under Clean Fog}

Figure 4 shows the dependences of leakage current on applied voltage for clean samples under clean fog at low, medium and high humidity. The figure indicates that leakage current increases almost linearly with applied voltage at clean condition. Increase of humidity result in a slight increase of leakage current magnitude. The increase of humidity at clean condition slightly reduced the surface resistance from $145.7 \mathrm{M} \Omega$ at low $\mathrm{RH}$ ro $134.5 \mathrm{M} \Omega$ at medium $\mathrm{RH}$ and $115.8 \mathrm{M} \Omega$ at high $\mathrm{RH}$.

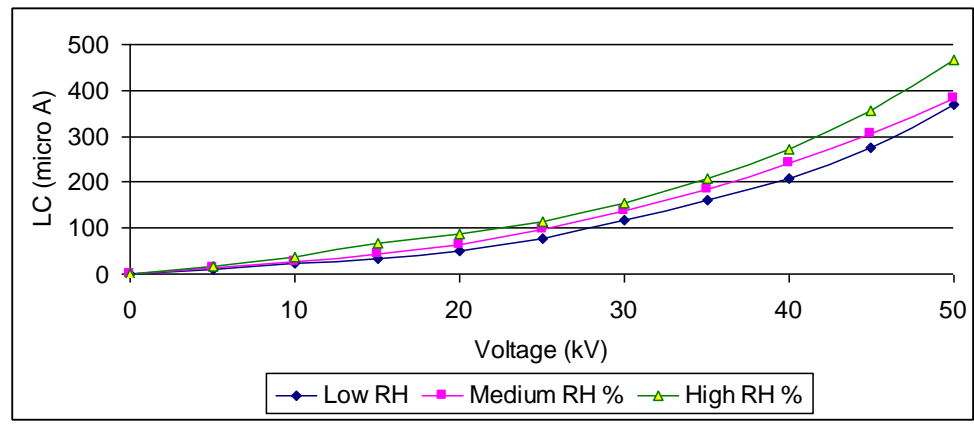

Figure 4 Dependences of leakage current on applied voltage under low, medium and high humidity

\subsection{Leakage Current Characteristics of Clean Samples under Salt Fog}

Figure 5 shows the dependences of leakage current on applied voltage for clean samples under salt fog with fog conductivity varied from $0.6 \mathrm{mS} / \mathrm{cm}$ to 4.0 $\mathrm{mS} / \mathrm{cm}$ at low (a), medium (b) and high humidity (c) under applied voltage ranged from $5 \mathrm{kV}$ to $50 \mathrm{kV}$. Figure 5 (a) showed that at low RH the magnitude of leakage current slightly increased with applied voltage. LC magnitude varied from less than $250 \mu \mathrm{A}$ at applied voltage of $5 \mathrm{kV}$ for all samples to about 2300 $\mu \mathrm{A}$ for salt fog conductivity of more than $1.2 \mathrm{mS} / \mathrm{cm}$. No flashover was found at this condition. Significant increase of LC magnitude was observed compared to those of clean samples under clean fog at all RH. The increase of LC magnitude was due to smaller surface resistance of the clean samples under salt fog. The resistance varied form $63.6 \mathrm{~m} \Omega$ at fog of $0.6 \mathrm{mS} / \mathrm{cm}$ to $20.5 \mathrm{~m} \Omega$ at $4.0 \mathrm{mS} / \mathrm{cm}$. 


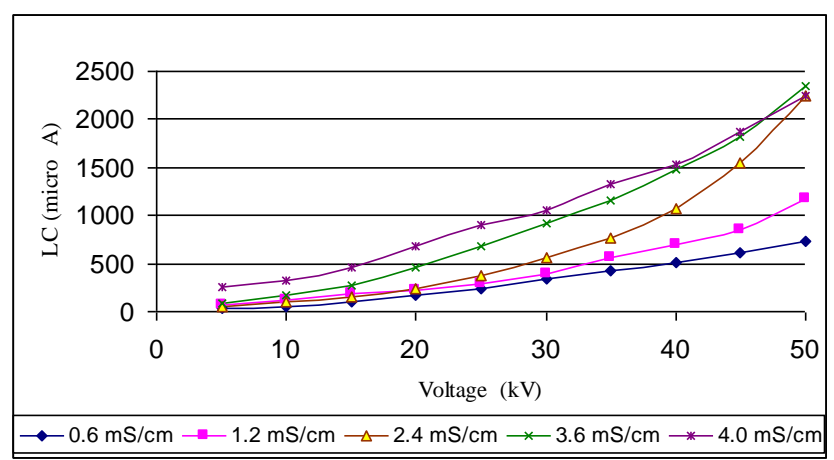

(a)

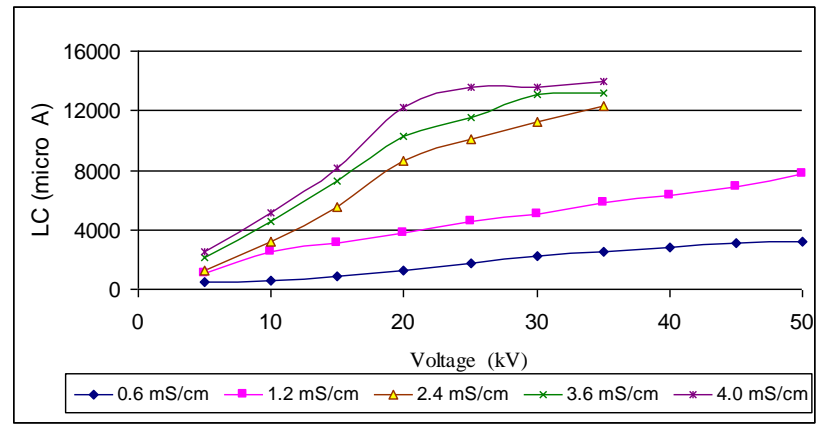

(b)

Figure 5 Dependences of LC magnitude on applied voltage for clean samples under salt fog of different conductivity.

Figure 5(b) showed the LC dependency on applied voltage at different fog conductivities. At fog of $0.6 \mathrm{mS} / \mathrm{cm}$ and $1.2 \mathrm{mS} / \mathrm{cm}$ LC magnitude increased almost linearly with applied voltage. No Flashover was observed up to $50 \mathrm{kV}$. Non linear dependency of LC magnitude on applied voltage was clearly observed at fog of $2.4 \mathrm{mS} / \mathrm{cm}$ and higher with applied voltage of larher than 20 $\mathrm{kV}$. During this condition electric arc appeared with large distortion of LC waveforms which will be explained later. Flashover was observed at $40 \mathrm{kV}$ for $2.4 \mathrm{mS} / \mathrm{cm}, 37.8 \mathrm{kV}$ for $3.6 \mathrm{mS} / \mathrm{cm}$ and $37 \mathrm{kV}$ for $4.0 \mathrm{mS} / \mathrm{cm}$.

\subsection{Leakage Current Characteristics of kaolin-polluted Samples under salt fog}

Figure 6 showed the dependences of LC magnitude on applied voltage for kaolin polluted samples under salt fog with fog conductivity varied from 0.6 $\mathrm{mS} / \mathrm{cm}$ to $4.0 \mathrm{mS} / \mathrm{cm}$ at (a) low and (b) high humidity. Figure 6(a) showed that at low RH the magnitude of leakage current slightly increased with applied 
voltage and only slight deviation from each other up to applied voltage of 25 $\mathrm{kV}$. LC magnitude varied from less than $500 \mu \mathrm{A}$ at applied voltage of $5 \mathrm{kV}$ for all samples to about $1100 \mu \mathrm{A}$ at applied voltage of $25 \mathrm{kV}$. At higher applied voltage, the increasing rate of LC magnitude increased with the salt fog conductivity. The figure indicated an Ohmic behavior of insulator sample (i.e. LC almost linearly increased with the applied voltage). No flashover was found at this condition for applied voltage up to $50 \mathrm{kV}$. Compared to those from clean samples (i.e. figure 4(a)) the LC magnitude was almost twice. This was caused by the higher reduction of surface resistivity since kaolin-polluted samples had higher ability to absorb salt fog compared to clean samples.

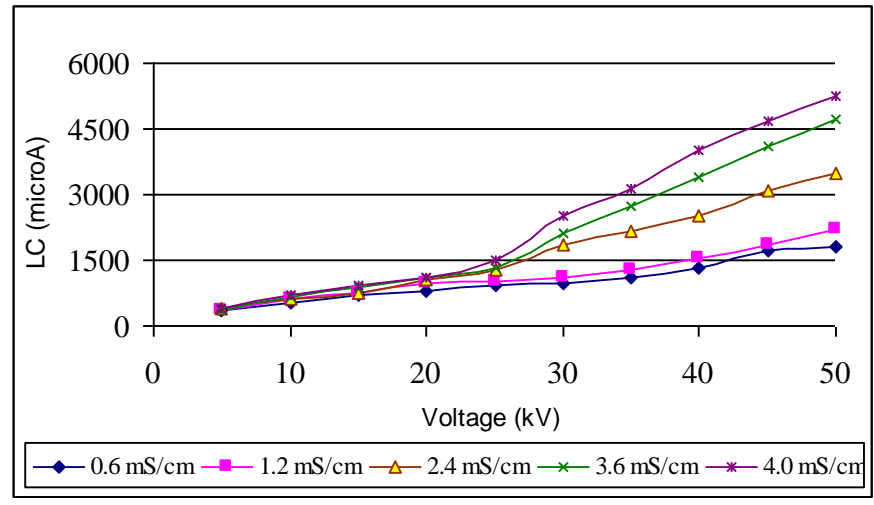

(a)

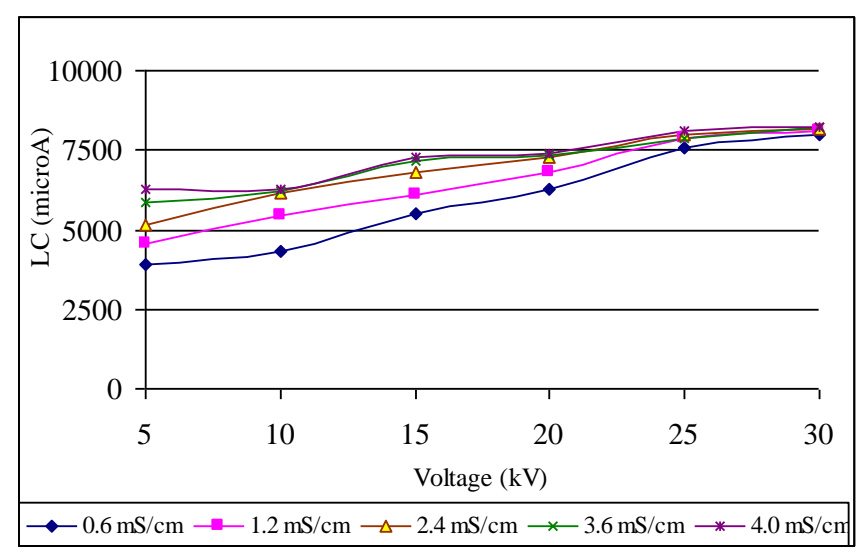

(b)

Figure 6 Dependences of LC magnitude on applied voltage of kaolin-polluted samples under salt fog at (a) low RH and (b) high RH. 
Figure 6(b) described the dependence of LC magnitude on applied voltage for kaolin-polluted samples under salt fogs at high RH. LC magnitude increased with applied voltage and fog conductivity. However, at applied voltage of 30 $\mathrm{kV}$ almost constant LC magnitude was observed. This was correlated with the appearance of arc and large distortion of LC waveforms. This will be discussed later in this paper.

\subsection{Leakage Current Characteristics of kaolin-salt polluted Samples under clean fog}

Figure 7 shows typical leakage current magnitude of kaolin-salt polluted insulators as a function of applied voltage under clean fog at (a) low RH and (b) high RH. Figure 7(a) shows that the discrepancies of LC magnitudes of different pollution levels at low RH is larger at higher applied voltage. This indicates that the effect of kaolin-salt pollution becomes stronger at higher voltage. Similar pattern was reported for glass insulator [23]. Figure 7(b) shows that at high RH the LC magnitude was higher. Under high humidity, the water molecules were absorbed by pollutant leading to the increase of surface conductivity and LC magnitude $[24,25]$. However, at high RH large discrepancy of LC magnitude was not observed at high applied voltage. This was caused by the fact that at high LC magnitude the drying effect took place and the effect of high $\mathrm{RH}$ reduced leading to the reduction of LC magnitude.

Table 1 Surface resistance (Rs) of sample under various conditions.

\begin{tabular}{lcccc}
\hline \multicolumn{1}{c}{ Sample } & $\begin{array}{c}\text { Conductivity } \\
(\mathbf{m S} / \mathbf{c m})\end{array}$ & $\begin{array}{c}\text { Rs at Low } \\
\mathbf{R H} \\
(\mathbf{M} \boldsymbol{\Omega})\end{array}$ & $\begin{array}{c}\text { Rs at Medium } \\
\mathbf{R H}(\mathbf{M} \boldsymbol{)})\end{array}$ & $\begin{array}{c}\text { Rs at High } \\
\mathbf{R H} \\
(\mathbf{M} \boldsymbol{\Omega})\end{array}$ \\
\hline $\begin{array}{l}\text { Clean sample under } \\
\text { clean fog }\end{array}$ & - & 145.7 & 134.5 & 115.8 \\
& 0.6 & 63.6 & 21.9 & 16.6 \\
$\begin{array}{l}\text { Clean sample under salt } \\
\text { fog }\end{array}$ & 1.2 & 43.8 & 9.6 & 7.3 \\
& 2.4 & 22.8 & 8.5 & 3.6 \\
& 3.6 & 22.4 & 7.6 & 2.6 \\
& 4.0 & 20.5 & 7.5 & 2.4 \\
$\begin{array}{l}\text { Kaolin-polluted under } \\
\text { salt fog }\end{array}$ & 0.6 & 32.8 & 27.7 & 11.3 \\
& 1.2 & 26.9 & 20.8 & 10.4 \\
& 2.4 & 14.8 & 14.3 & 8.3 \\
& 3.6 & 13.9 & 10.2 & 6.8 \\
& 4.0 & 13.7 & 8.8 & 5.7 \\
\hline
\end{tabular}




\begin{tabular}{lcccc}
\hline \multicolumn{1}{c}{ Sample } & $\begin{array}{c}\text { Conductivity } \\
(\mathbf{m S} / \mathbf{c m})\end{array}$ & $\begin{array}{c}\text { Rs at Low } \\
\mathbf{R H} \\
(\mathbf{M} \boldsymbol{\Omega})\end{array}$ & $\begin{array}{c}\text { Rs at Medium } \\
\mathbf{R H}(\mathbf{M} \boldsymbol{\Omega})\end{array}$ & $\begin{array}{c}\text { Rs at High } \\
\mathbf{R H} \\
(\mathbf{M} \boldsymbol{\Omega})\end{array}$ \\
\hline & 0.6 & 4.9 & 3.4 & 2.6 \\
Kaolin-salt polluted & 1.2 & 4.1 & 3.3 & 2.5 \\
under clean fog & 2.4 & 3.5 & 3.1 & 2.4 \\
& 3.6 & 3.4 & 2.9 & 2.3 \\
& 4.0 & 3.3 & 2.8 & 2.2 \\
\hline
\end{tabular}

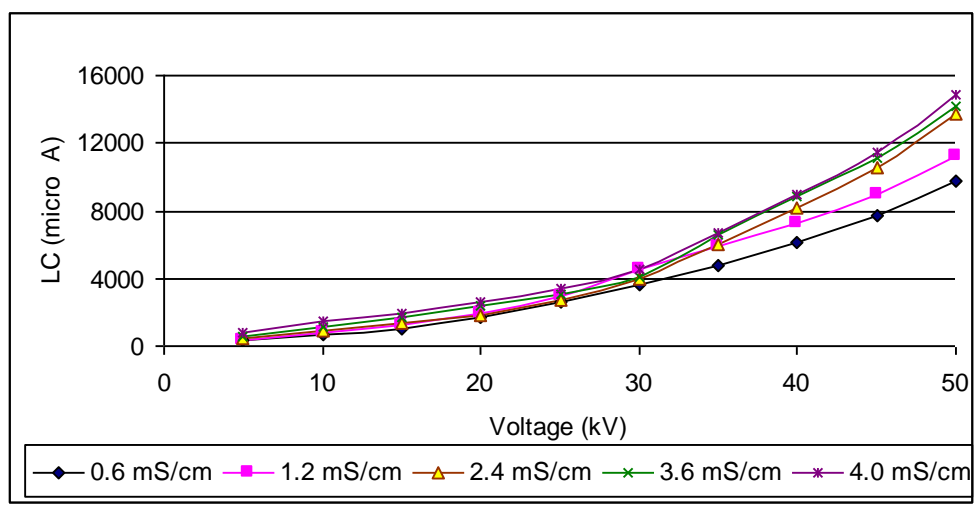

(a)

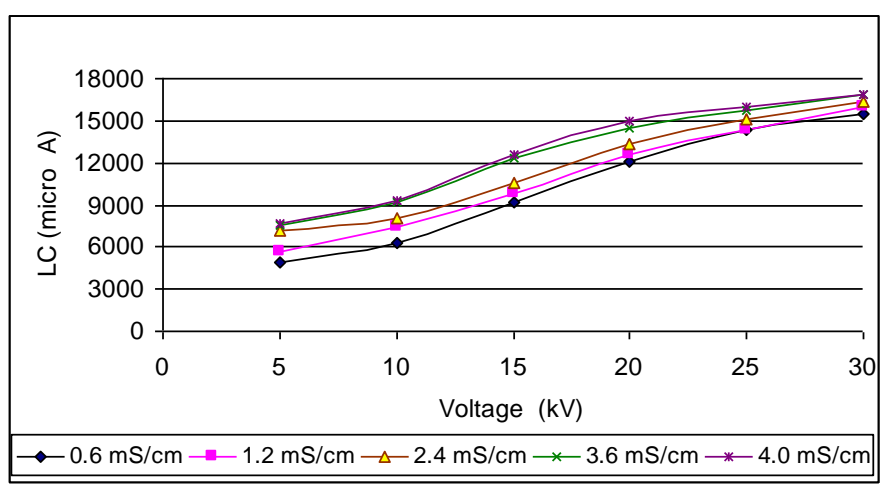

(b)

Figure 7 Dependence of LC magnitude on applied voltage for kaolin-salt polluted samples under clean fog at (a) low RH and (b) high RH. 


\subsection{Dependent of Leakage Current Waveforms on Applied} Voltage at Low RH

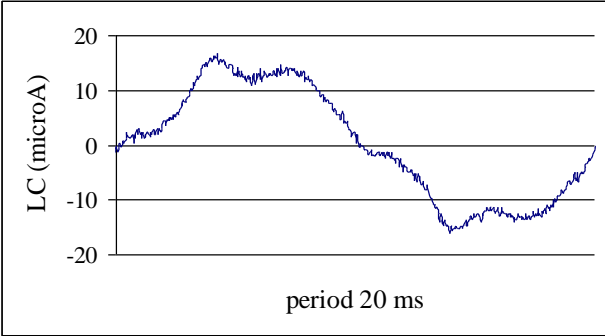

$5 \mathrm{kV}$

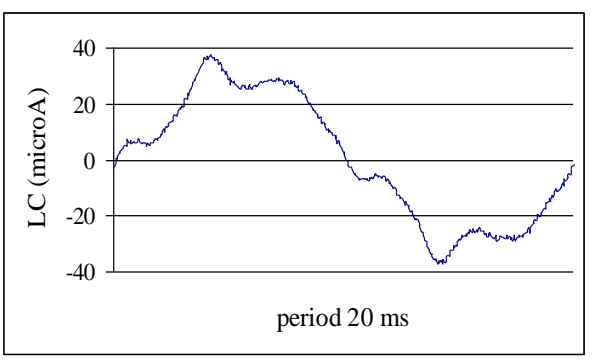

$10 \mathrm{kV}$

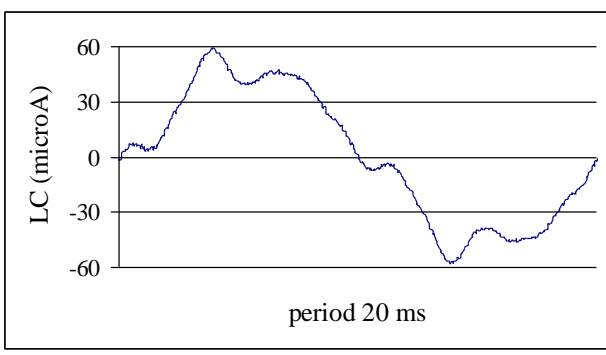

$15 \mathrm{kV}$

(a)
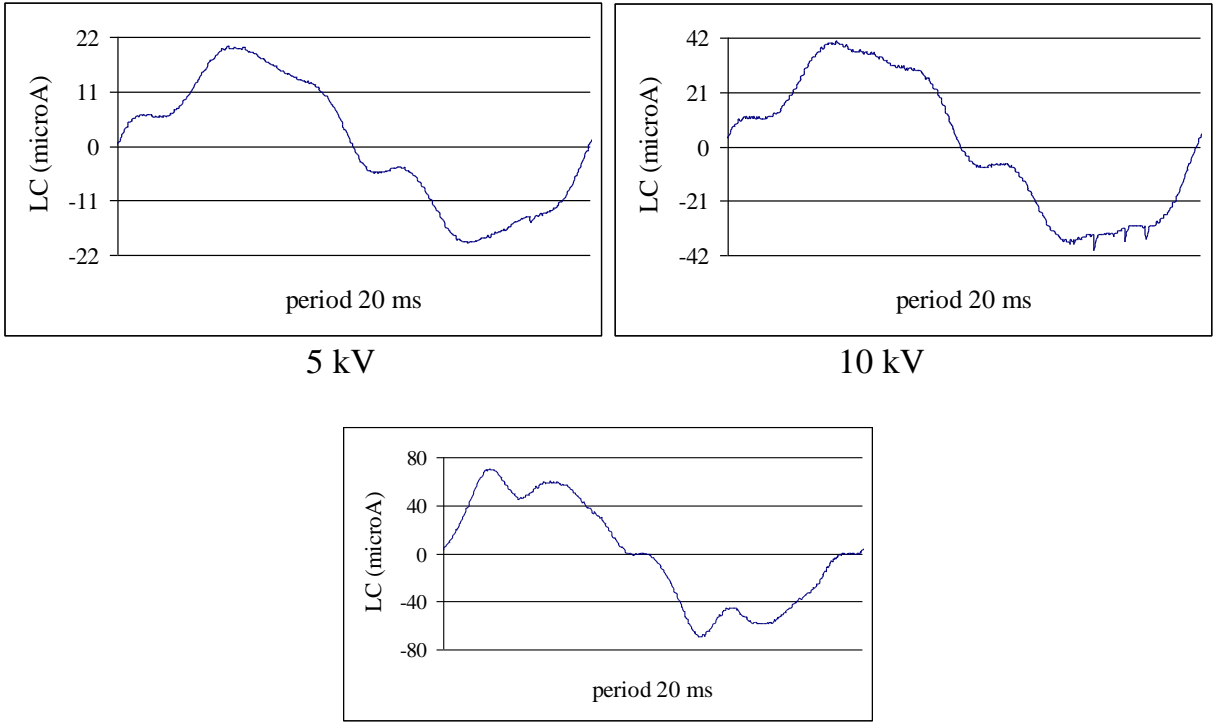

$15 \mathrm{kV}$

(b) 


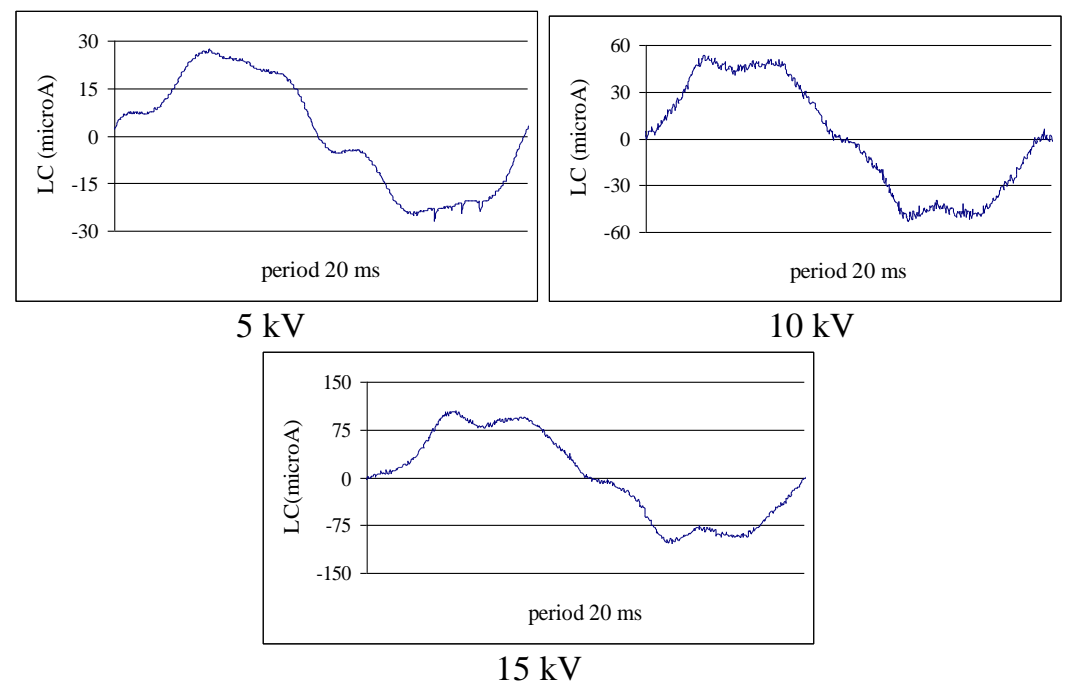

(c)

Figure 8 Typical leakage current waveforms for clean insulators under clean fog and applied voltages of $5 \mathrm{kV}, 10 \mathrm{kV}$ and 15 at (a) low RH (b) medium RH and (c) high RH.

Figure 8 shows typical leakage current waveforms of clean samples under clean fog and applied voltage of 5,10 and $15 \mathrm{kV}$ at (a) low RH (b) medium RH and (c) ahigh RH. Al figure clearly show that LC waveforms are distorted from sinusoidal form. The amplitude of LC increased with applied voltage and humidity. At a given $\mathrm{RH}$, the waveform distortion as indicated by THD increased with applied voltage. However, at a given applied voltage THD decreased with RH. The comparison of THD for clean sample at different RH and applied voltage are shown in Figure 9.

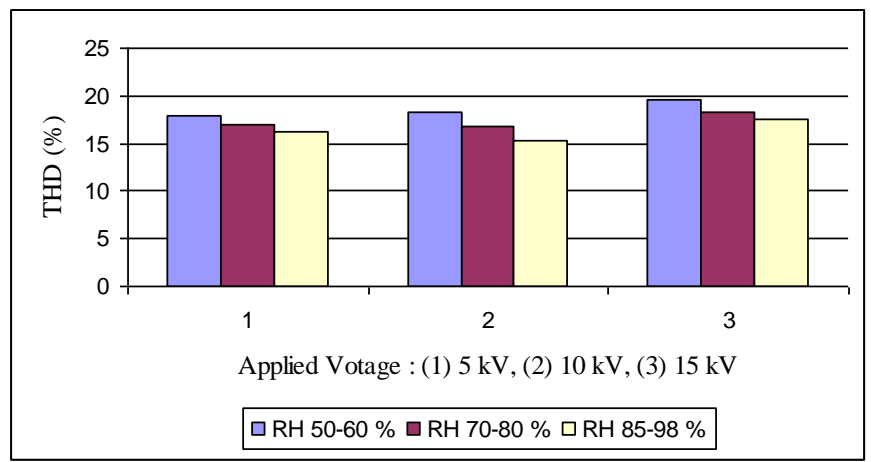

Figure 9 Typical THD of LC waveforms for clean samples under clean fog. 
3.6 LC for Kaolin Polluted under Salt Fog $3.6 \mathrm{mS} / \mathrm{cm}$

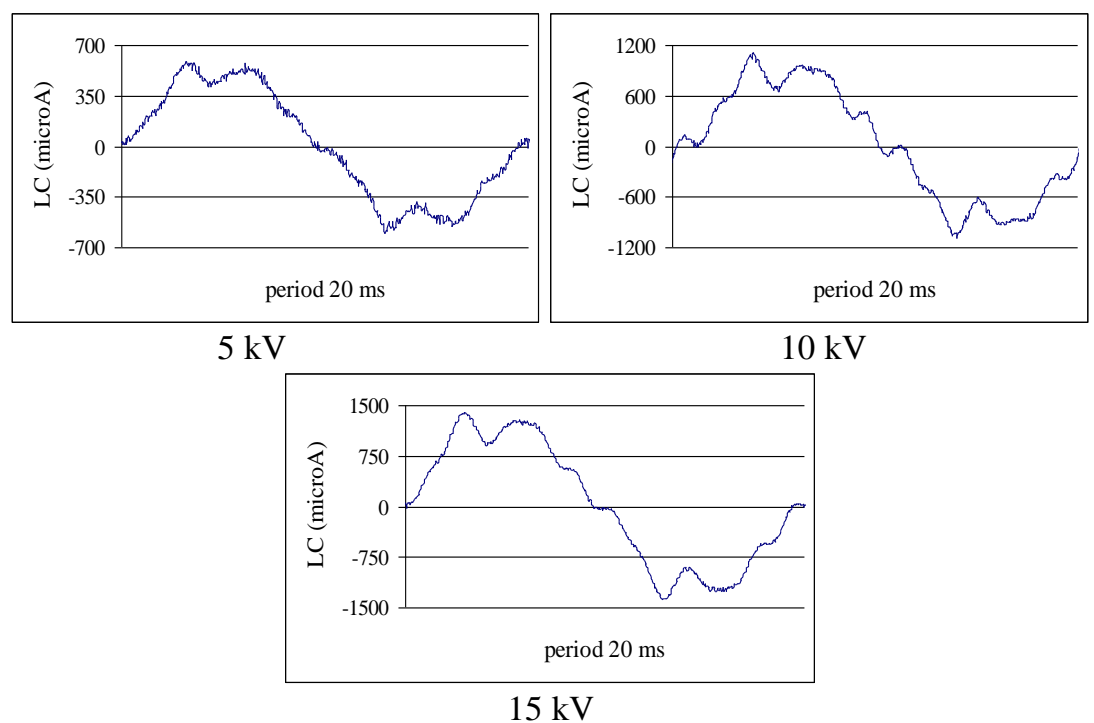

(a)
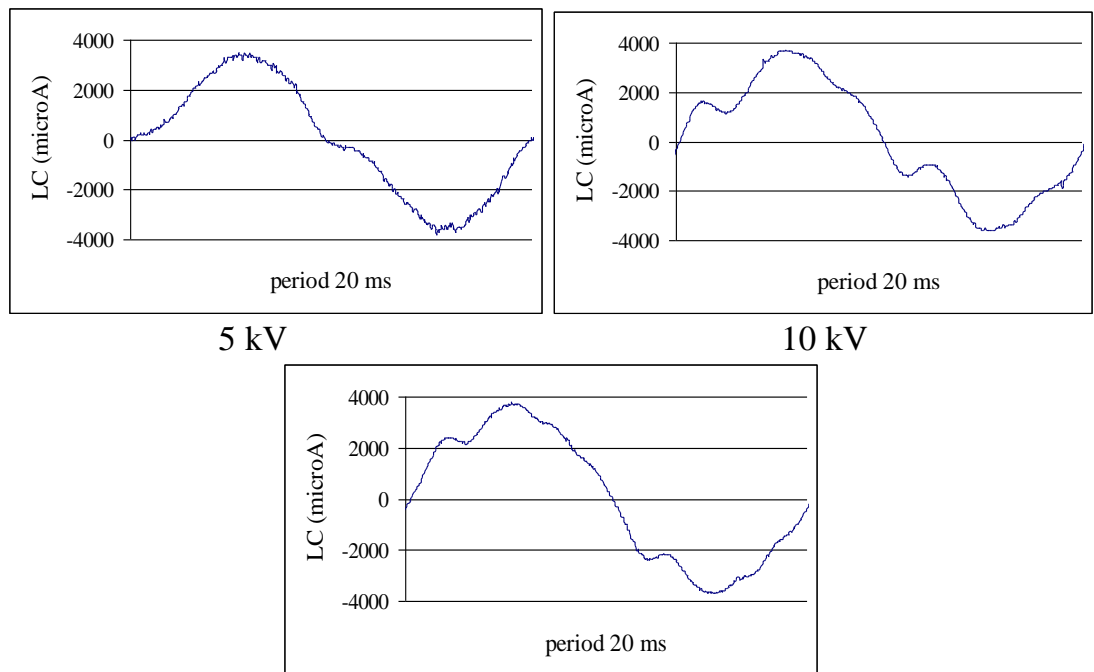

$15 \mathrm{kV}$

(b) 

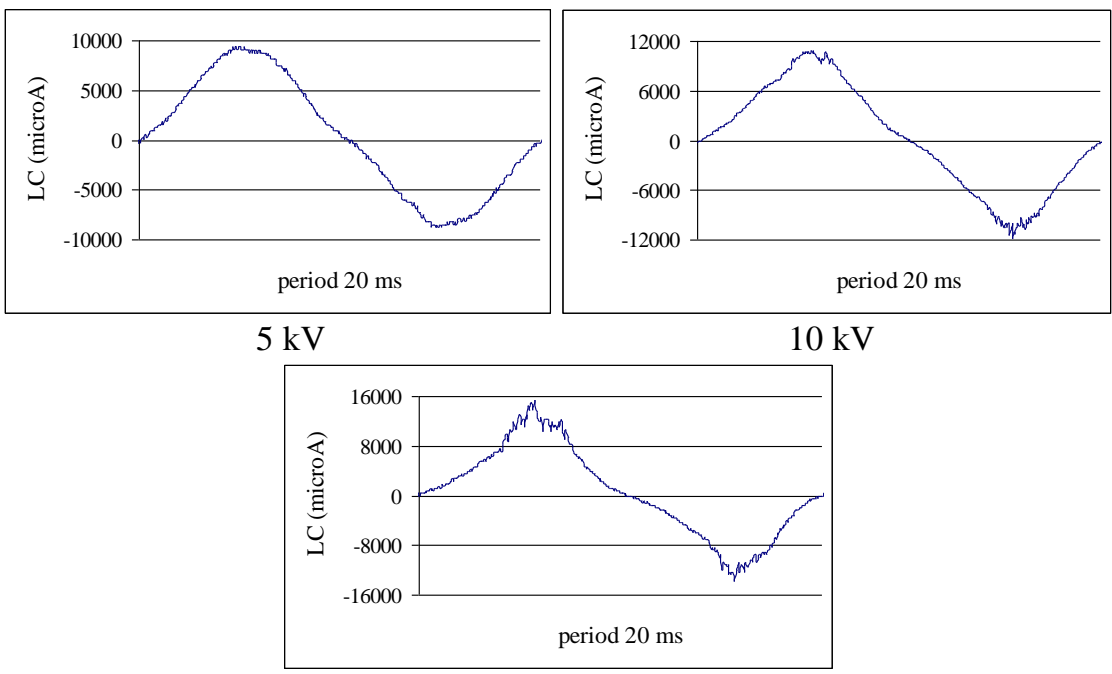

$15 \mathrm{kV}$

(c)

Figure 10 Typical LC Waveforms for kaolin polluted samples under salt fog of $3.6 \mathrm{mS} / \mathrm{cm}$ at (a) low RH (b) medium RH and (c) high RH.

Figure 10 shows the typical LC Waveforms for kaolin polluted samples under salt fog of $3.6 \mathrm{mS} / \mathrm{cm}$ at (a) low RH (b) medium RH and (c) high RH. The figure clearly indicates that at a given RH the LC amplitude increased with the applied voltage. At low RH and low applied voltage, the LC waveforms were strongly distorted. The distortion decreased with RH. However, at high RH and high applied voltage, the THD increased greatly. The THD values of samples with various values of applied voltages and RH are shown in Figure 11.

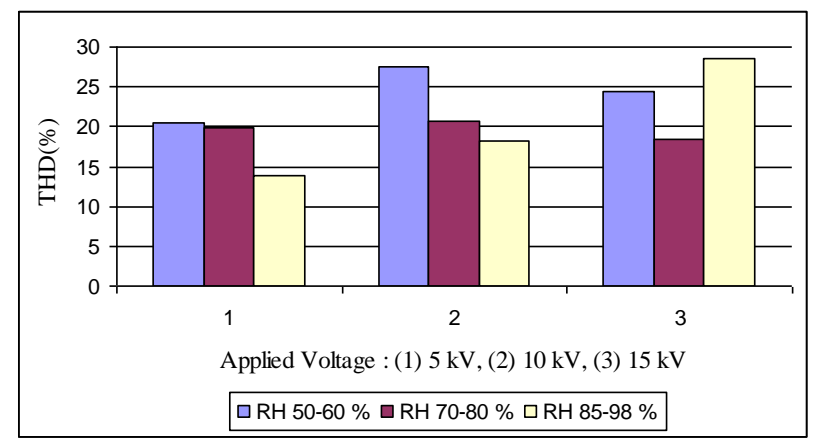

Figure 11 THD for kaolin polluted under salt fog. 


\subsection{LC for Kaolin-Salt Polluted at $3.6 \mathrm{mS} / \mathrm{cm}$ under Clean Fog}

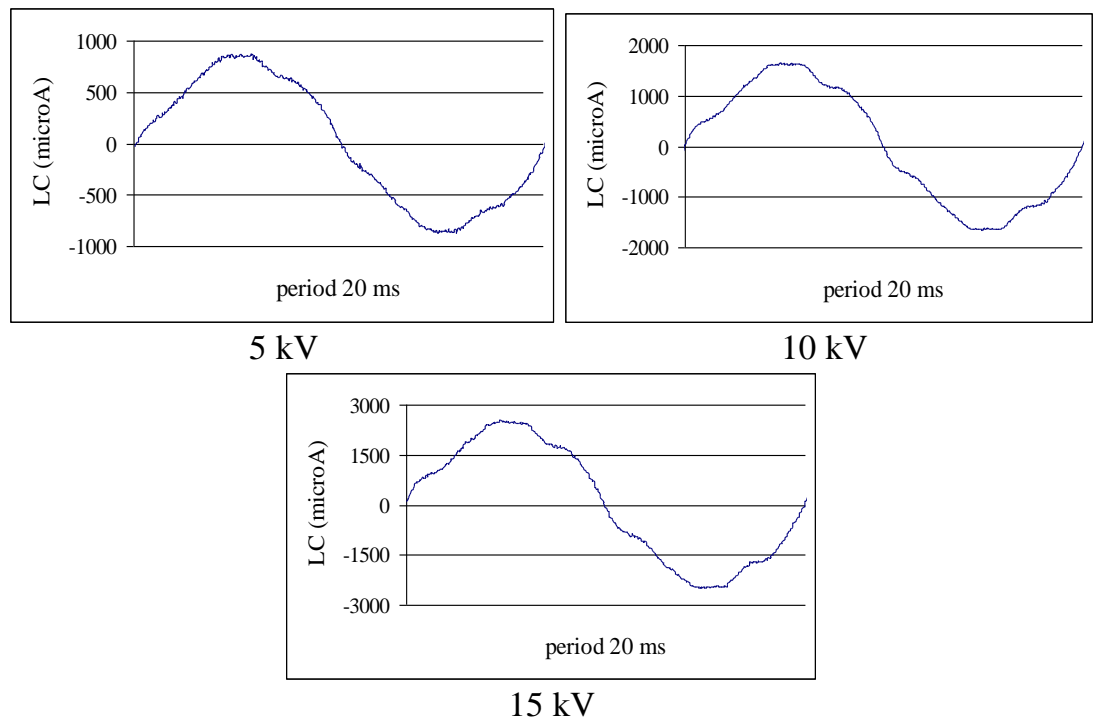

(a)
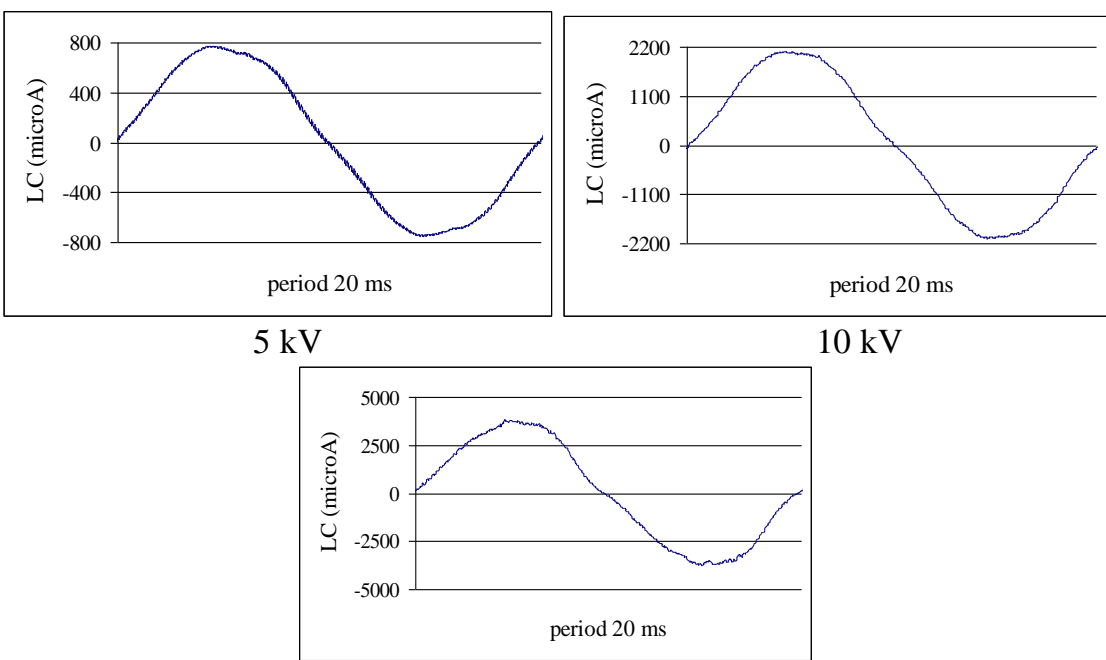

$15 \mathrm{kV}$

(b) 


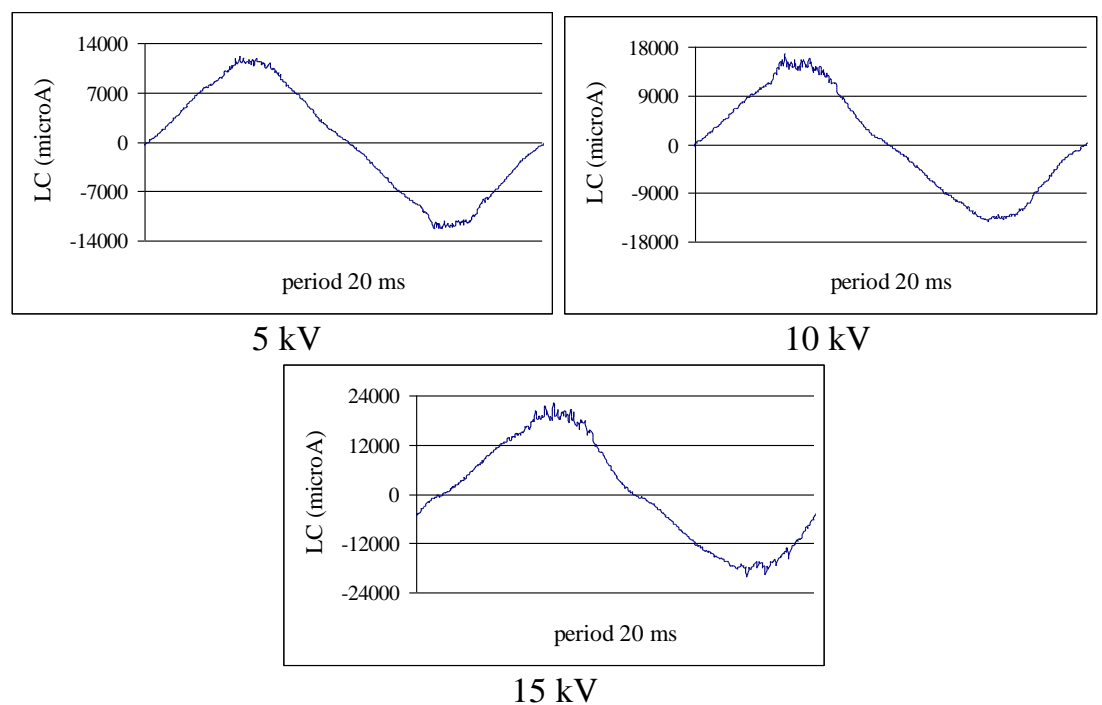

(c)

Figure 12 Typical LC waveforms for kaolin-salt polluted at $3.6 \mathrm{mS} / \mathrm{cm}$ under clean fog and applied voltage of 5, 10 and $15 \mathrm{kV}$ at (a) low RH (b) medium RH and (c) high $\mathrm{RH}$

Figure 12 shows typical LC waveforms for kaolin-salt polluted at $3.6 \mathrm{mS} / \mathrm{cm}$ under clean fog and applied voltage of 5, 10 and $15 \mathrm{kV}$ at (a) low $\mathrm{RH}$ (b) medium RH and (c) high RH. The figure clearly indicates that LC magnitude of kaolin-salt polluted samples greatly affected by both applied voltage and humidity. In general the LC magnitude significantly larger than those from kaolin-polluted samples under salt fog condition at same conductivity but the distortion of the LC waveforms from its sinusoidal was smaller as indicated by THD. THD was slightly increased with applied voltage and strongly affected by humidity. At high RH the LC amplitude was large and the waveform distortion was also high especially at the peak of the LC waveforms. This correlated with local arc due to corona since corona usually occurs at the highest part/peak of the applied voltage [26]. Harmonic analysis indicated that odd harmonics components especially $3^{\text {rd }}, 5^{\text {th }}$ and $7^{\text {th }}$ appeared with relatively high magnitude. Similar behavior was reported for suspension insulators [27] and post pin EPDM insulator [28]. This symmetrical LC waveform with dominant odd harmonic components was correlated with the appearance of spark on the sample surface at high RH which enhanced the distortion of LC waveforms leading to the increase of THD. The values of THD as function of voltage and RH is shown in Figure 13. 


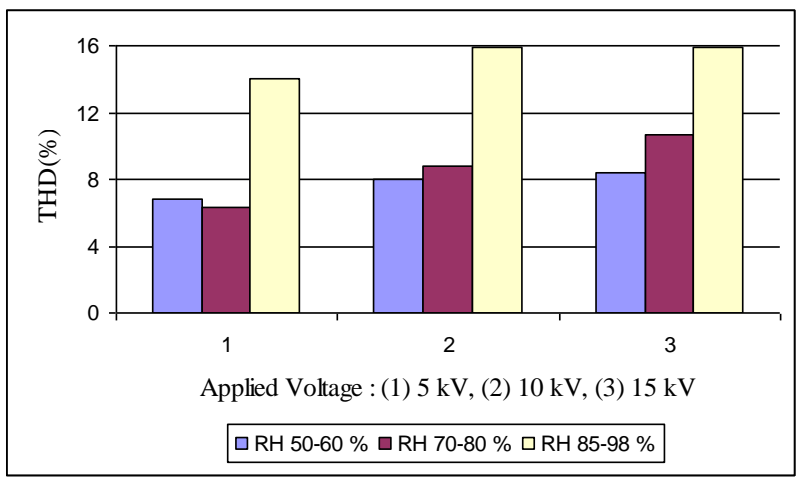

Figure 13 THD for kaolin-salt polluted at $3.6 \mathrm{mS} / \mathrm{cm}$ under clean fog.

\subsection{Arc during Tracking}

Electric arc on the sample was investigated using incline plane experiment according to IEC 587. The sample was mounted in a chamber at an angle of $45^{\circ}$. The peristaltic pump was used to continously deliver electrolite at a particular conductivity at fixed flow-rate of $0.15 \mathrm{ml} / \mathrm{min}$. AC voltage of $12 \mathrm{kV}$ was applied. The arc on the sample surface was observed using a camera and the corresponding leakage current was measured using LC measurement system as described before.

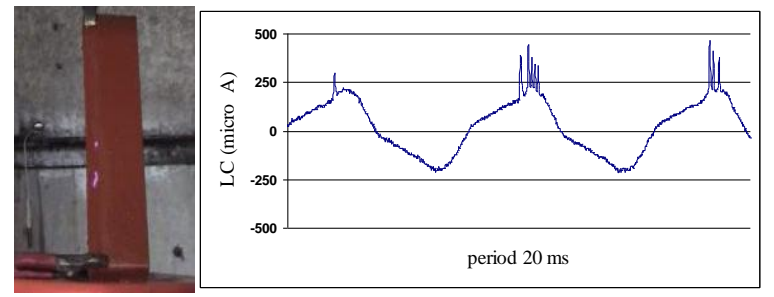

$0.3 \mathrm{mS} / \mathrm{cm}$, Irms $=139 \mathrm{~mA}, \mathrm{THD}=31.7 \%$

(a)

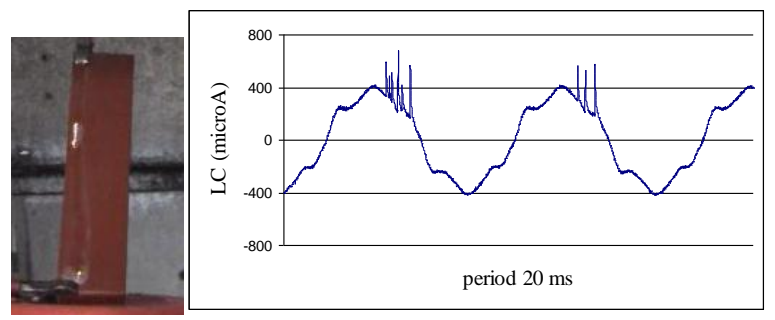

$0.6 \mathrm{mS} / \mathrm{cm}$, Irms $=278 \mathrm{~mA}$, THD $=52.7 \%$

(b) 


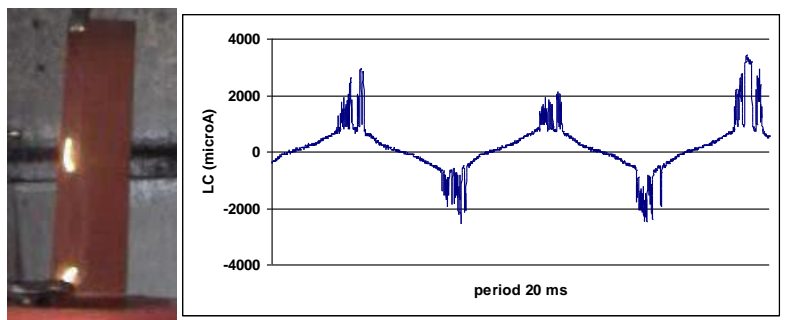

$0.9 \mathrm{mS} / \mathrm{cm}$, Irms $=873 \mathrm{~mA}, \mathrm{THD}=55.1 \%$

(c)
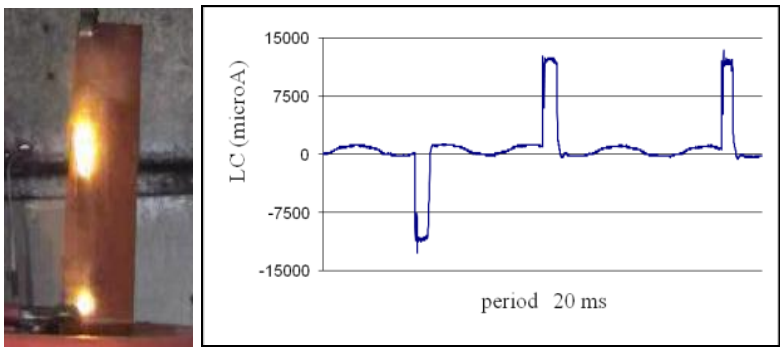

(d)

Figure 14 Photographs of arcs on the samples and corresponding LC waveforms from incline plane test at different pollutant conductivity.

Figure 14 shows photographs of arcs on the samples and corresponding LC waveforms at pollutant conductivity of (a) $0.3 \mathrm{mS} / \mathrm{cm} \mathrm{(b)} 0.6 \mathrm{mS} / \mathrm{cm}$ (c) 0.9 $\mathrm{mS} / \mathrm{cm}$ and (d) $12 \mathrm{mS} / \mathrm{cm}$. At pollutant conductivity of $0.3 \mathrm{mS} / \mathrm{cm}$, small arc with length of $2 \mathrm{~cm}$ appeared at $223 \mathrm{~s}$ after the voltage application. The LC waveform indicated distortion at the peak of positive half cycle. This indicated that arc discharge was initiated from the surface of the pollutant and not from the surface of the sample. The results with pollutant conductivity of $0.6 \mathrm{mS} / \mathrm{cm}$ indicated similar characteristics with larger magnitude and higher THD as shown in Figure 14(b).

Figure 14(c) is photograph and LC waveform under pollutant conductivity of $0.9 \mathrm{mS} / \mathrm{cm}$. The LC waveform became symmetrical and the distortion concentrated around the peak of the waveforms.

Figure 14(d) shows a different pattern of LC waveform obtained under pollutant conductivity of $1.2 \mathrm{mS} / \mathrm{cm}$. The LC amplitude was high. The LC waveforms were strongly distorted with THD of $65.7 \%$. This is a highly distorted LC waveform which correlates with a large arc due to dry band formation [29]. The parameters of arc obtained from this experiment are summarized in Table 2. 
Table 2 Arc parameters during tracking at incline plane test.

\begin{tabular}{c|ccccc}
\hline \multirow{2}{*}{$\begin{array}{c}\text { Arc } \\
\text { Parameter }\end{array}$} & \multicolumn{5}{|c}{ Conductivity of pollution (mS/cm) } \\
\cline { 2 - 6 } & $\mathbf{0 . 3}$ & $\mathbf{0 . 6}$ & $\mathbf{0 . 9}$ & $\mathbf{1 . 2}$ & $\mathbf{1 . 5}$ \\
\hline Time (s) & 223 & 185 & 121 & 98 & 67 \\
Length (cm) & 2 & 3 & 3 & 3,5 & 5 \\
Intensity (lux) & 8,1 & 9,5 & 13,4 & 15,7 & 18,6 \\
Irms ( $\mu \mathrm{A})$ & 139 & 278 & 873 & 3798 & 9384 \\
THD (\%) & 31.7 & 52.7 & 55 & 65.7 & 72.9 \\
\hline
\end{tabular}

\section{Conclusion}

Leakage current and arc characteristics for epoxy resin under clean and salt fogs have been investigated. Experimental results indicated that LC magnitude on clean samples was slightly affected by RH. However, under salt fog, RH greatly affected the LC magnitude. The flashover voltage of clean samples under salt fog reduced significantly for fog conductivity of more than $1.2 \mathrm{mS} / \mathrm{cm}$. Kaolinpolluted samples under salt fog showed an Ohmic behaviour. The LC magnitude was high and a large discrepancy of LC magnitude was observed for high applied voltage of larger than $25 \mathrm{kV}$. The largest LC magnitude was observed on salt-kaolin polluted samples under clean fog at high RH. LC waveforms analysis indicated that in general $\mathrm{LC}$ waveforms were distorted from sinusoidal. For clean samples under clean fog, THD of LC decreased with RH but slightly increased with the applied voltage. Large distortion at the peak of LC waveform was observed on kaolin polluted sample under salt fog of 3.6 $\mathrm{mS} / \mathrm{cm}$ and high $\mathrm{RH}$ and high applied voltage. This correlates with corona arc on the sample surface. Similar behaviour was observed on kaolin-salt polluted samples under clean fog. Tracking arc experiment indicated that arc length LC magnitude and arc intensity increased with the pollutant conductivity. The THD also significantly increased with pollutant conductivity. At conductivity of less than $0.6 \mathrm{mS} / \mathrm{cm}$ the unsymmetrical LC waveforms were obtained. However, symmetrical LC waveforms were observed for conductivity of 0.9 and 1.2 $\mathrm{mS} / \mathrm{cm}$. The change of LC magnitude and waveform at different condition of samples may be useful for the diagnostics of insulator condition. 


\section{References}

[1] Gorur, R.S., Cherney, E.A. \& Burnham, J.T., Outdoor Insulators, Ravi Gorur Inc, Arizona, 1999.

[2] Cherney, E.A. \& Stonkus, D.J., Non Ceramic Insulators for Transmission Lines, IEEE Trans. Power Delivery, 4, pp. 2214-2220, 1989.

[3] Izumi, K. \& Kadotani, K., Application of Polymeric Outdoor Insulators in Japan, IEEE Trans. DEI, 6(5), pp. 595-604, 1999.

[4] Gustavsson, T.G., Gubanski, S.M., Hilborg, Karllsson, S., Gedde, U.W., Aging of Silicone Rubber under AC and DC Voltage in a Coastal Environment, IEEE Trans.s on Dielectrics and Electrical Insulation, 8(6), pp. 1029-1039, 2001.

[5] Gubanski, S.M., Dernfalk, A., Wallstrom, S., Carlsson, S., Performance and Diagnostics of Biologically Contaminated Insulators, Proc. 8th International Conf. On Properties and Appl. Diel. Materials, Bali, June 2006, pp. 23- 30, 2006.

[6] Gautam, B.K., Yamazaki, T., Yamada, K., Matsushita, S., Sakanishi, K., Matsuoka, R., Effect of Non-Soluble Contaminations on the Flasover Voltage of Polymeric Insulators, Proc. 8th International Conf. On Properties and Appl. Diel. Materials, Bali, June 2006, pp. 534- 537, 2006.

[7] Gorur, R.S., Cherney, E.A., Hackam, R., A Comparative Study of Polymer Insulating materials under Salt Fog, IEEE Trans., EI, 21(2), pp. 175-182, 1986.

[8] Lambert, P.J., et al, Final Report on the Clean Fog Test for HVAC Insulators, IEEE Trans., Power Delivery, 2(4), pp. 1317-1326, 1987.

[9] De la O, A., Chang, J., Gorur, R., AC clean fog test on non ceramic insulating materials and a comparation with porcelain, IEEE Trans. Power Delivery, 9(4), 1994.

[10] Gorur, R.S., Montesinos, J., Varadadesikan, L., Simmons, S., Shah, W., A Laboratory Test for Tracking and Errosion Resistance of HV Outdoor Insulation, IEEE Trans. on DEI, 4(6), pp. 767-774, 1997.

[11] Yoshimura, N., Kumagai, S., Research in Japan on the Tracking phenomena of Electrical nsulating Materials, IEEE EI Magazine, 13(5), pp. 8-18, 1997.

[12] Naito, K., Matsuoka, R., Irie, T., Kondo, K., Test Method and Results for Recent Outdoor Insulation in Japan, IEEE Trans., DEI, 6(5), pp. 732743, 1999.

[13] Kim, S.H., Cherney, E.A., Hackam, R., Artificial Testing and Evaluation of RTV Coatings in Salt Fog Chamber, IEEE Trand, EI, 20(4), pp. 797805, 1991.

[14] Gorur, R.S., Sundararajan, Amburgey, O.G., Contamination Performance of Polymeric Insulating materials used for Outdoor Insulation Applicatrion, IEEE Trans., EI, 24(4), pp. 713-716, 1989. 
[15] Suwarno, Suppression of Leakage Current and Improving Insulator voltage withstand using silocone compound coating, $7^{\text {th }}$ Int. Power Eng. Conf., Singapore, pp. 324-328, 2007.

[16] Suwarno, Wiratmaja, I., Improving the Performances of Outdoor ceramic Insulators under Severe Conditions by Using Silicone Compound Coatings, WSEAS Transaction on Power System, 1(6), pp. 1001-1008, June 2006.

[17] Jahromi, A.N., Cherney E.A., Jayaram, S.H., Simon, L.C., Aging Characteristics of RTV SIR Insulating Coatings, IEEE Trans., DEI, 15(2), pp. 444-452, 2008.

[18] Kumagai, S., Yoshimura, N., Impacts of Thermal Aging and Water Absorption on Surface Electrical and Chemical properties of Epoxy resin, IEEE Trans., DEI, 7(3), pp424-431, 2000.

[19] Gorur, R.S., Montesinos, J., Electrical Performance of Cycloaliphatic Epoxy Materials and Insulators for Outdoor Use, IEEE Trans. Power Delivery, 15(4), pp. 1274-1278, 2000.

[20] IEC Pub. 507, Artificial Pollution Tests on High Voltage Insulators to be Used in ac System, 1991.

[21] IEC Pub. 60-1, High Voltage Test techniques, Part I, 1995.

[22] IEC Pub. 587, The Method for Evaluating Resistance to Tracking of Electrical Insulating Materials under Severe Ambient Conditions, 1984.

[23] Mekhladi, A., Namane, D., Bauazabia, S., Beroul, A., Flashover of Discontinous Pollution Layer on HV Insulators, IEEE Trans.s on Dielectrics and Electrical Insulation, 6(6), pp. 900-906, 1999.

[24] Suwarno, Study on the waveform of leakage current on the $20 \mathrm{kV}$ post-pin ceramic insulators under various conditions, Proc. Intl. Symp. On Electr. Insul. Mats., pp. 387-390, 2001

[25] Karady, George, G., Flashover Mechanism of Nonceramic Insulator, IEEE Transactions on Dielectrics and Electrical Insulation, 6(5), October 1999.

[26] Suwarno, Mizutani, T., Pulse Sequence Analysis of Discharges in Air, Liquid and Solid Insulating Materials, KIEE Journal of Electrical Engineering and Technology, 1(4), pp. 528-533, 2006.

[27] Suda, T., Frequency Characteristics of Leakage Current Waveforms of a String of Suspension Insulators, IEEE Trans. on Power Delivery, 20(1), pp 481-487, 2005.

[28] Suwarno, Leakage Current Waveforms of Outdoor Polymeric Insulators and Possibility of Appalication for Diagnostics of Insulator Conditions, KIEE Journal of Electrical Engineering and Technology, 1, pp. 114-119, 2006.

[29] AH El Haq, Jayaram, S.H., Cherney, E.A., Fundamental and Low Frequency Components of $L C$ as a diagnostic Tool to Study Aging of RTV and HTV SIR in Salt Fog, IEEE Trans.DEI, 10(1), pp. 128-136, 2003. 